\title{
Sturge-Weber Syndrome Type III
}

\author{
(1) Hande Gazeteci Tekin1, (1) Sarenur Gökben22, (1) Sanem Yılmaz2, (1) Hasan Tekgül2, (1) Gül Serdaroğlu² \\ ${ }^{1}$ Çiğli Region Training Hospital, Clinic of Pediatric Neurology, İzmir, Turkey \\ 2Ege University Faculty of Medicine, Department of Pediatric Neurology, İzmir, Turkey
}

\begin{abstract}
Sturge-Weber syndrome (SWS) is a neurogenetic disease with an incidence of 1 in 20.000-50.000 live births. The less common form, which can be difficult to diagnose and only involves leptomeningeal angioma, has been defined as Type III SWS. A 5.5-month-old male patient with normal neuromotor development presented with right sided partial seizures, which had been occurring frequently for the previous two days and could not be controlled. A cranial magnetic resonance imaging showed pathological contrasts in the cortical regions involving the left hemisphere and in the leptomeningeal structures. We aim to present the case of an infant with SWS, which unlike the classical form was unidentifiable in physical examination and diagnosed using imaging methods.

Keywords: Sturge-Weber, without nevus, epilepsy, children
\end{abstract}

\section{Introduction}

The classical triad of Sturge-Weber syndrome is a port-wine stain on the face, glaucoma and leptomeningeal angiomas. While Type I might include the whole triad, Type II presents with the involvement of the skin without leptomeningeal angiomas. Type III Sturge-Weber syndrome is the rarest subtype and presents with leptomeningeal involvement without the port-wine stain on the face (1-3). Only a few cases of this type have been reported, and its incidence is unknown (4-7). This subtype is generally diagnosed based on the findings of leptomeningeal angiomas in contrast brain magnetic resonance imaging (MRI) scans and calcifications in the same region via brain computed tomography (CT) scans of patients presenting with seizures $(4,5)$. Here, we present the case of a 5.5-month-old patient with Type III SturgeWeber syndrome presenting with seizures.

\section{Case Report}

A 5.5-month-old male patient with age-appropriate mental and motor development was referred to our hospital with right sided partial seizures occurring several times a day. His physical examination and neurological examination were normal. The partial seizures were unresponsive to intravenous diazepam, diphenylhydantoin and midazolam. Intravenous levetiracetam was administered and the seizures were partially controlled. His electroencephalogram showed isolated sharp wave discharges in the temporal regions of the left hemisphere, and a slow back-ground rhythm of the left hemisphere compared to the right hemisphere (Figure 1). Cranial MR imaging of the patient revealed pathological contrasts in the cortical regions involving the left hemisphere and in the leptomeningeal structures (Figure 2a). Brain MR angiography and venography were normal. Lumber puncture was performed and serum samples were taken with the

\section{Address for Correspondence}

Hande Gazeteci Tekin MD, Çiğli Region Training Hospital, Clinic of Pediatric Neurology, Izmir, Turkey Phone: +90 5055985681 E-mail: gazetecihande@yahoo.com.tr ORCID ID: orcid.org/0000-0002-4407-164X Received: 29.01.2017 Accepted: 29.03.2017

${ }^{\circ}$ Copyright 2018 by Ege University Faculty of Medicine, Department of Pediatrics and Ege Children's Foundation The Journal of Pediatric Research, published by Galenos Publishing House. 


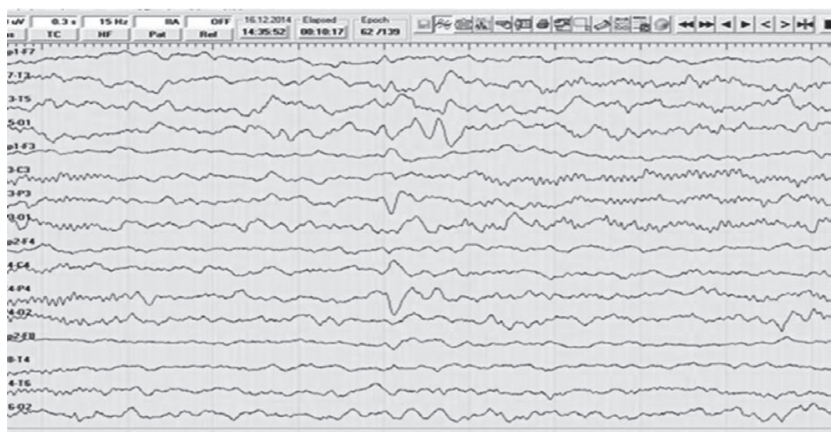

Figure 1. Electroencephalogram; isolated sharp wave discharges in the temporal regions of the left hemisphere, and slow back-ground rhythm of the left hemisphere compared to the right hemisphere

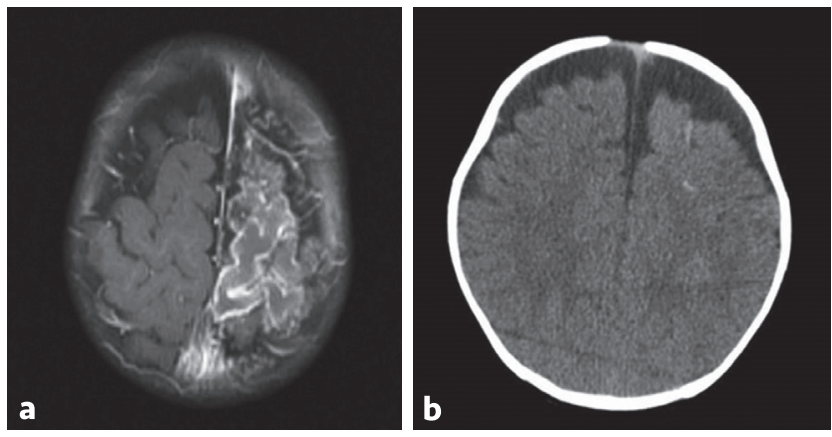

Figure 2. a) Cranial magnetic resonance; pathological contrasts in the cortical regions involving the left hemisphere and in the leptomeningeal structures, b) brain computed tomography; calcifications in the left hemisphere

pre-diagnosis of meningoencephalitis. Intravenous acyclovir therapy was started. Biochemical and serological tests were normal. Repeated contrast brain MR imaging on the $7^{\text {th }}$ day indicated no change. Brain CT which was performed with the pre-diagnosis of Sturge-Weber syndrome revealed calcifications in the involved hemisphere (Figure 2b). The ophthalmological examination was normal, glaucoma was not determined. The patient's antiviral treatment was ceased and antiepileptic treatment was continued. The patient has been followed-up and diagnosed with Sturge-Weber syndrome Type III. His seizures are under control using diphenylhydantoin and levetiracetam.

Informed family consent was taken from parents before publishing his diagnosis and treatment details.

\section{Discussion}

Sturge-Weber syndrome is a neurocutaneous disorder characterized by facial and leptomeningeal angiomas, glaucoma, hemiparesis, stroke-like attacks, seizures and also atrophy and calcifications in the brain. Abnormal intrauterine arterial and venous flow pattern, abnormal connections between deep and superficial veins, associated stasis and subsequent thrombosis and ischemia are blamed in the etiology (1). Type III Sturge-Weber syndrome is the rarest subtype and it is difficult to diagnose as it does not involve skin abnormalities. Similar to our patient, 75-90\% of patients with this subtype present with seizures and receive diagnosis using imaging methods. While glaucoma is seen in approximately $30 \%$ of the patients with classical Sturge-Weber syndrome, it is often not seen in patients with Type III Sturge-Weber syndrome, which is attributed to the absence of facial angiomas. However, headache and migraine-like attacks are frequently seen $(7,8)$. Atrophy, neuronal losses and astrogliosis can be seen in the brain tissue underlying the leptomeningeal angiomas, which may lead to structural impairments in the cortex. Proteins and Ca2 entering cells through increased vascular permeability cause a crystallization, which helps diagnosis. Gadoliniumenhanced T1-weighted imaging and susceptibility-weighted imaging performed at the early pre-symptomatic phase are useful in the detection of leptomeningeal angiomas (9). Recently developed post contrast fluid-attenuated inversion recovery imaging and high-resolution blood oxygen level dependent MR venography may also increase sensitivity in detecting the leptomeningeal angioma (10). In the presented case, although there was no other finding compatible with Sturge-Weber syndrome, the absence of other clinical clues for meningoencephalitis and no change in the radiological findings after antiviral therapy raised the suspicion for Sturge-Weber syndrome. Radiological findings are of great importance in the diagnosis of this subtype, since these patients do not present with dermatological symptoms. Leptomeningeal angiomas detected in patients can be confused with viral encephalitis and arteriovenous anomalies. Although cranial MRI is performed in most patients, this subtype is diagnosed via calcifications observed in cranial CT. It will be possible to establish a rapid and definitive diagnosis with the identification of genetic causes of the disorder. Sturge-Weber Type III can mimic different neurological diseases. Radiological findings are of great importance in the diagnosis of this subtype since these patients do not present with dermatological symptoms. Cranial CT and MR may be useful if the diagnosis is uncertain.

\section{Ethics}

Informed Consent: Informed family consent was taken from parents before publishing his diagnosis and treatment details.

Peer-review: External and internal peer-reviewed.

\section{Authorship Contributions}

Surgical and Medical Practices: H.G.T., Concept: H.G.T., S.Y., G.S., Design: H.G.T., H.T., Data Collection and Processing: H.G.T., Analysis and Interpretation: S.G., G.S., Literature Search: H.G.T., H.T., Writing: H.G.T., G.S.

Conflict of Interest: No conflict of interest was declared by the authors. 
Financial Disclosure: The authors declared that this study has received no financial support.

\section{References}

1. Sudarsanam A, Ardern-Holmes SL. Sturge-Weber syndrome: from the past to the present. Eur J Paediatr Neurol 2014;18:25766.

2. Shirley MD, Tang H, Gallione C), et al. Sturge Weber syndrome and port-wine stains caused by somatic mutation in GNAQ. N Engl J Med 2013;368:1971-9.

3. Korf BR, Bebin EM. Neurocutaneous Disorders in Children. Pediatr Rev 2017;38:119-28.

4. Zanzmera P, Patel T, Shah V. Diagnostic dilemma: SturgeWeber syndrome, without facial nevus. I Neurosci Rural Pract 2015;6:105-7.

5. Jagtap SA, Srinivas G, Radhakrishnan A, Harsha KJ. A clinician's dilemma: Sturge-Weber syndrome 'without facial nevus'!! Ann Indian Acad Neurol 2013;16:118-20.
6. Mukherjee D, Kundu R, Niyogi PC. Sturge-Weber syndrome type III. Indian / Pediatr 2015;82:97-8.

7. Jordan PR, lqbal M, Prasad M. Sturge-Weber syndrome type 3 manifesting as 'Status migrainosus'. BMJ Case Rep 2016:2016.

8. Sujansky E, Conradi S. Sturge Weber Syndrome: age of onset of seizures and glaucoma and the prognosis of affected children. I Child Neurol 1995;10:49-58.

9. $\mathrm{Hu}$ J, Yu Y, Juhasz C, et al. MR susceptibility weighted imaging (SWI) complements conventional contrast enhanced T1 weighted MRI in characterizing brain abnormalities of Sturge Weber Syndrome. I Magn Reson Imaging 2008;28:300-7.

10. Mentzel HJ, Dieckmann A, Fitzek C, Brandl U, Reichenbach JR, Kaiser WA. Early diagnosis of cerebral involvement in Sturge Weber syndrome using high-resolution BOLD MR venography. Pediatr Radiol 2005;35:85-90. 